\title{
Input, stocks and output flows of urban residential building system in Beijing city, China from 1949 to 2008
}

\author{
Dan $\mathrm{Hu}^{\mathrm{a}, *}$, Fang You ${ }^{\mathrm{a}}$, Yanhua Zhao ${ }^{\mathrm{a}}$, Ye Yuan $^{\mathrm{a}}$, Tianxing Liu ${ }^{\mathrm{a}}$, Aixin Cao ${ }^{\mathrm{a}}$, Zhen Wang ${ }^{\mathrm{b}}$, Junlian Zhang $^{\mathrm{c}}$ \\ a State Key Lab of Urban E' Regional Ecology, Research Center for Eco-Environmental Sciences, Chinese Academy of Sciences, Beijing 100085, China \\ ${ }^{\mathrm{b}}$ School of Environmental Sciences and Engineering, Beijing Forestry University, Beijing, China

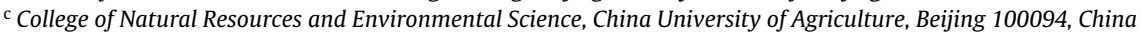

\section{A R T I C L E I N F O}

\section{Article history:}

Received 11 July 2007

Received in revised form 22 March 2010

Accepted 24 March 2010

\section{Keywords:}

Urban residential buildings

Flows of construction materials

Construction wastes

Temporal changes

Beijing city

\begin{abstract}
A B S T R A C T
Urban residential buildings are formed, maintained and reformed by different external material and energy flows, and their behaviors of input, accumulation and output are characterized by their architectural factors and modes of use that usually determine the consumption of material and energy of a building at its overall life cycle.

In this research, we took Beijing city, a rapid developing city as a case study, and examined material flows of urban residential building system based on a survey of typical residential buildings in the urban areas of Beijing city. The quantitative analysis were made to describe the input, transformation/accumulation, and output of building materials from the year 1949 to 2008, and a comparative analysis was done to identify the differences of material uses among the buildings with different architectural structures as masonry-concrete, and steel-concrete.

During the period from 1949 to 2008, there were six main materials of cement, sand, gravel, steel, bricks and timber used in urban residential building system in Beijing. The total amount of material imported into the system was $5.1 \times 10^{8} \mathrm{t}$, among which the accumulated amount was $4.7 \times 10^{8} \mathrm{t}$, an accumulation rate of $92.5 \%$, and the total of building wastes reached $3.9 \times 10^{7} \mathrm{t}$. Among the buildings with two architectural structures, the total amount of material use for buildings with steel-concrete structure was larger than masonry-concrete. It was found that the buildings with steel-concrete structure experienced a rapid increase since the year 1979 in Beijing. As a result of rapid urban development, the large-scale reformation and demolishment of urban old buildings also led to a rapid growth of the amount of building wastes. And the building wastes generated in the process of reformation and demolition began to exceed that produced in the process of new buildings construction. The amount of building wastes generated from 2004 to 2008 accounted for $52.2 \%$ of the total that generated from 1949 to 2008 .

From this research, the rapid development of Beijing's residential building system in the past 60 years became a big ecological pressure for urban sustainable building development. It is important to change the traditional model of urban construction, and develop some sustainable or ecologically friendly construction technologies to enhance the capacity of recycling and reuse of residential building wastes for realizing a sustainable urban building construction and management in Beijing.
\end{abstract}

(c) 2010 Elsevier B.V. All rights reserved.

\section{Introduction}

Cities are a kind of open and complex ecosystems, just like life, which operate or develop in a dynamic way to exchange materials, energy and information with their surroundings. In the mid-period of last century, the analysis of urban material and energy flows was introduced to examine urban ecological processes (Wolman, 1965). Afterwards, a lot of researches on material and energy flows of urban ecosystems were conducted (Newcombe et al., 1978; Boyden

\footnotetext{
* Corresponding author. Tel.: +861062849199.

E-mail addresses: hudan@rcees.ac.cn, hrcees@vip.sina.com (D. Hu).
}

et al., 1981; Baccini and Brunner, 1991; Baccini, 1997; Newman, 1999; Decker et al., 2000; Mitchell et al., 2001; Warren-Rhodes and Koenig, 2001; Sahely et al., 2003; Barles, 2009). In addition, emergy analysis was also introduced to assess urban processes of materials and energy flows, and became an important methodological basis for analyzing urban ecosystems flows (Ulgiati and Brown, 1998; Haberl et al., 2004; Zhang et al., 2009).

The urban buildings are important components of urban ecosystems which produce ecological or environmental problems and have high associations with urban materials and energy flows, gradually becoming a great concern among ecologists, urban planners and administrators in the recent years. Usually, the research on urban construction flows focused on the temporal and spa- 


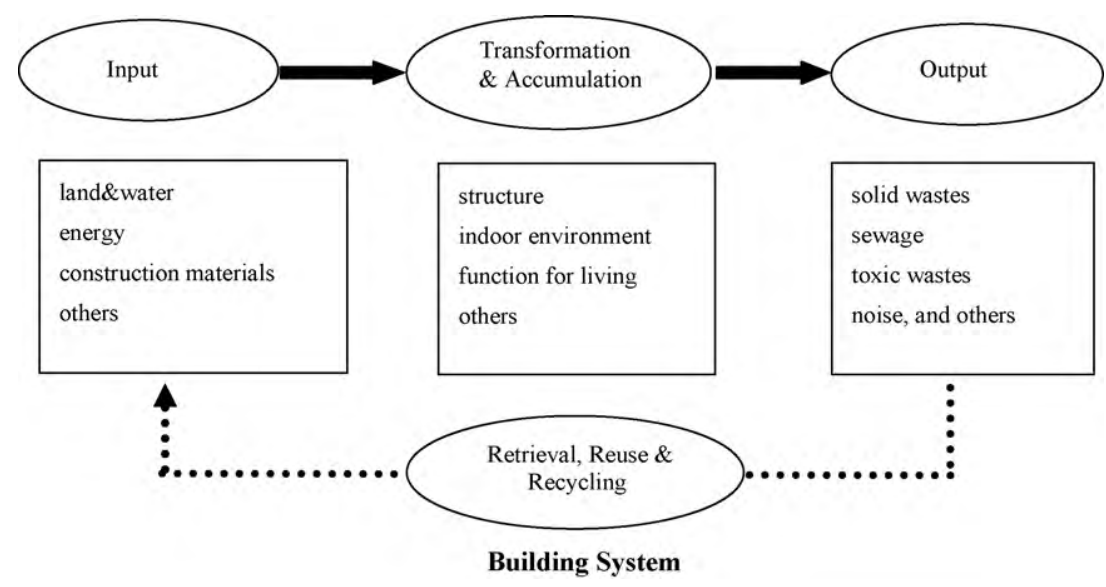

Fig. 1. A simplified conceptual model for dynamics of urban building system.

tial characteristics of construction materials or energy flows and their environmental or ecological impacts at the perspective of life cycle, which covers the entire process of urban construction activities from extraction of raw materials, processing, construction, use, reuse and recycle of constructive wastes (Johnstone, 2001; Chwieduk, 2003; Meillaud et al., 2005; Müller, 2006; Pulselli et al., 2007; Asif et al., 2007). Al-Rabghi and Douglas (2001) made a simulative analysis on influences of energy utilization on reformation of buildings. HOPE, COHOPE and ENEHOPE models were established to analyze direct and indirect material and energy flows of buildings and their environmental impacts (Tiwari, 2001; Theodosiou et al., 2005). A city-level analysis of building material and energy flows in Taipei city was conducted to show that sand and gravel occupied $90 \%$ of the total of material uses, and the emergy amount of constructive materials accounted for $46 \%$ of the total of the city (Huang and Hsu, 2003). In the different stages of building life cycle, the dominant periods of material and energy uses and environmental impacts are in the processes of building construction and its operation. In China, this occupied $50 \%$ of total uses of building energy (Zhao and Tong, 2003). A research on environmental impacts in the processes of building material selection and uses for small-size residential buildings was made in Southern France (Morel et al., 2001), and a national-level survey was conducted in Sweden to show that smaller environmental impacts appeared in the period of building maintenance and reformation than those in building construction, and environmental impacts from energy consumption and emission of wastewater accounted for a larger share in the total environmental impacts from buildings (Erlandsson and Borgb, 2003; Erlandsson and Levin, 2004).

China is currently experiencing rapid urbanization. The level of urbanization increases from $10.6 \%$ in 1949 to $45.7 \%$ in 2008 , and the urban population grew from 325 million in 1990 to 606 million in 2008 (State Statistical Bureau, 2009). Simultaneously, urban buildings are also in rapid growth. For example in Beijing, there was newly built residential area of $3.65 \times 10^{8} \mathrm{~m}^{2}$ in the 60 years from 1949 to 2008 , which was larger than 20 times of the total before 1949 (Beijing Municipal Bureau Statistics, 2009). In China, the use amount of constructive raw materials is annually more than 5 billion tons, and there is also waste gas emission of 110 million $\mathrm{m}^{3}$, wastewater of over 35.5 billion tons from construction activities. Along with urban construction, there is a considerable amount of constructive wastes generation, which accounts for about 15-20\% of total municipal solid wastes (Osmani et al., 2008).

In the present research, we take Beijing as a case study, and first introduced the methodological framework of analyzing the material and energy flows of residential building system, and presented an estimation of per unit area material constructive use for Beijing's residential building system in the process of building construction and reformation. Then, we selected some residential buildings with the two types of typical architectural structures to examine their flows of input, transformation/accumulation and output during the period from 1949 to 2008, and further made a comparison on the differences in material use among the two main types of architectural structures. After that, a Beijing material flows chart of residential buildings in a given period was established, finally some further discussions were made for the analysis of constructive materials flows in Beijing residential buildings.

\section{Analysis method}

\subsection{Analyzing scope for Beijing residential building system}

From a perspective of building life cycle, there are generally several temporal stages of material flows of residential buildings that are exploitation of raw materials, processing, construction, use and maintenance, reformation and demolishment as well as wastes disposal and recycling or reuses. In this study, all the residential buildings in the central areas of Beijing are selected as a residential building system, in which there are different material and energy flows and environmental impacts in each stage of its life cycle. Our study mainly focuses on its stages of construction, reformation and demolishment. The data needed in this study comes from our site survey of typical buildings and some statistical yearbooks of city construction of Beijing, and the temporal scope of study was from 1949 to 2008 , totaling 60 years.

\subsection{Conceptual model for flow dynamics of residential building system}

From an ecosystem point of view, exchanges of material and energy between residential building system and its surroundings, can be demonstrated with fluxes and rates of input, output and transformation and accumulation of materials and energy. There are three basic components in dynamic processes of residential building system, namely, imports of constructive materials or energy, transformation and accumulation as a stock of construction materials or energy within the system and outputs of constructive wastes, all of which form a complete process of building system dynamics (Fig. 1).

\subsubsection{Inputs of building system}

The construction, use or reformation of buildings consume various materials, water and energy. These materials 


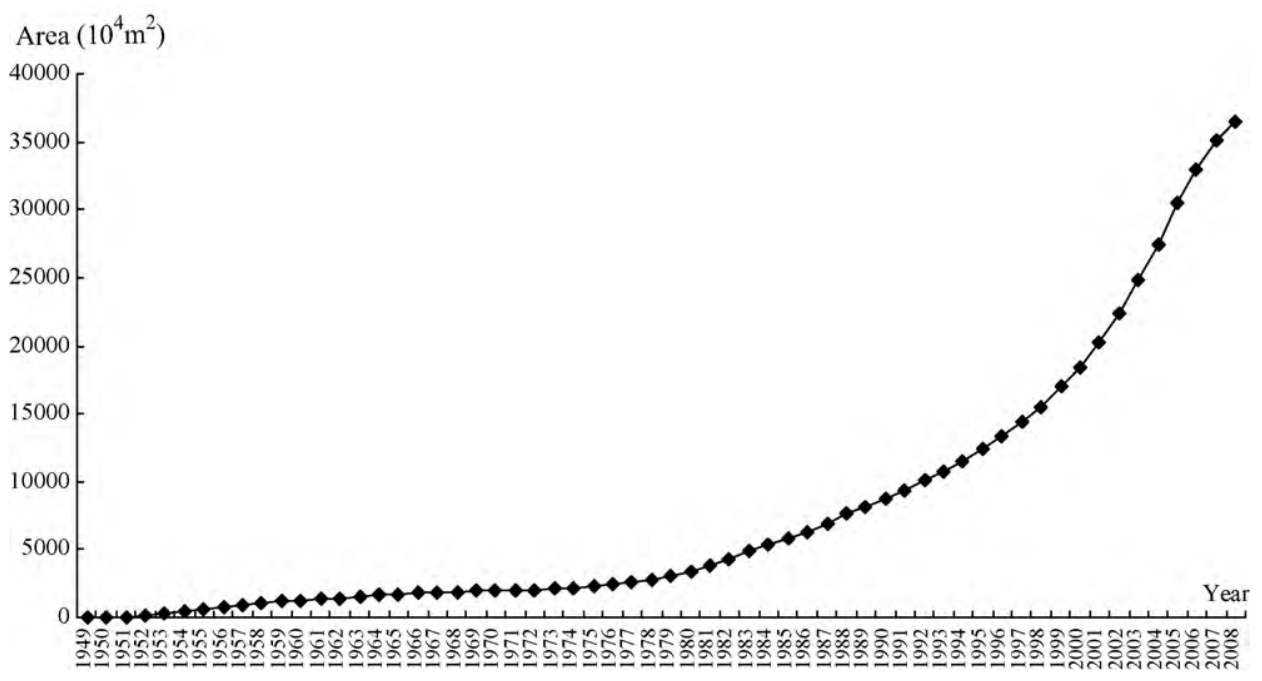

Fig. 2. The total finished area of residential buildings from 1949 to 2008 in Beijing.

and energy are defined as inputs of building system in this research.

\subsubsection{Outputs of building system}

There are different wastes generated from the dynamic processes of residential building system which often have some negative environmental impacts. The wastes mainly come from the three stages such as stages of building construction, of use and maintenance, and of reformation or demolishment, and are defined as outputs of building system in this research. In Beijing, some construction wastes can be recycled or reused and the others are treated in the form of landfill.

\subsubsection{Transformation and accumulation as a stock in the system}

In our research, residential buildings can be divided into three categories: buildings under construction, buildings in use, and buildings in reformation or demolishment. For the first case, most of constructive materials in the system are transformed and accumulated to be components of building stocks, the other small part becomes constructive wastes and is disposed away from the system. For the second case, the intensity of material transformation and accumulation is small while intensity of energy use is large. The accumulated constructive materials gradually wear away in different forms and are moved out of the system. The energy is also consumed and emitted in the form of heat and some types of waste gases in the processes of building use and maintenance. As for the third case, the original architectural structures or functions are altered or destroyed to some extent or completely, and some old materials can still be reused in different forms in this process, and the others useless are carried out of the system as wastes.

\subsection{Analyzing methods for the flow dynamics of residential building system}

At a perspective of life cycle, MFA (material flow analysis) or MEFA (material and energy flow analysis) method are introduced into this research to examine characteristics of dynamic activities of residential building system in Beijing from the stage of construction to reformation or demolishment (Warren-Rhodes and Koenig, 2001; Mitchell et al., 2001; Haberl et al., 2004; Ulgiati and Brown, 1998).

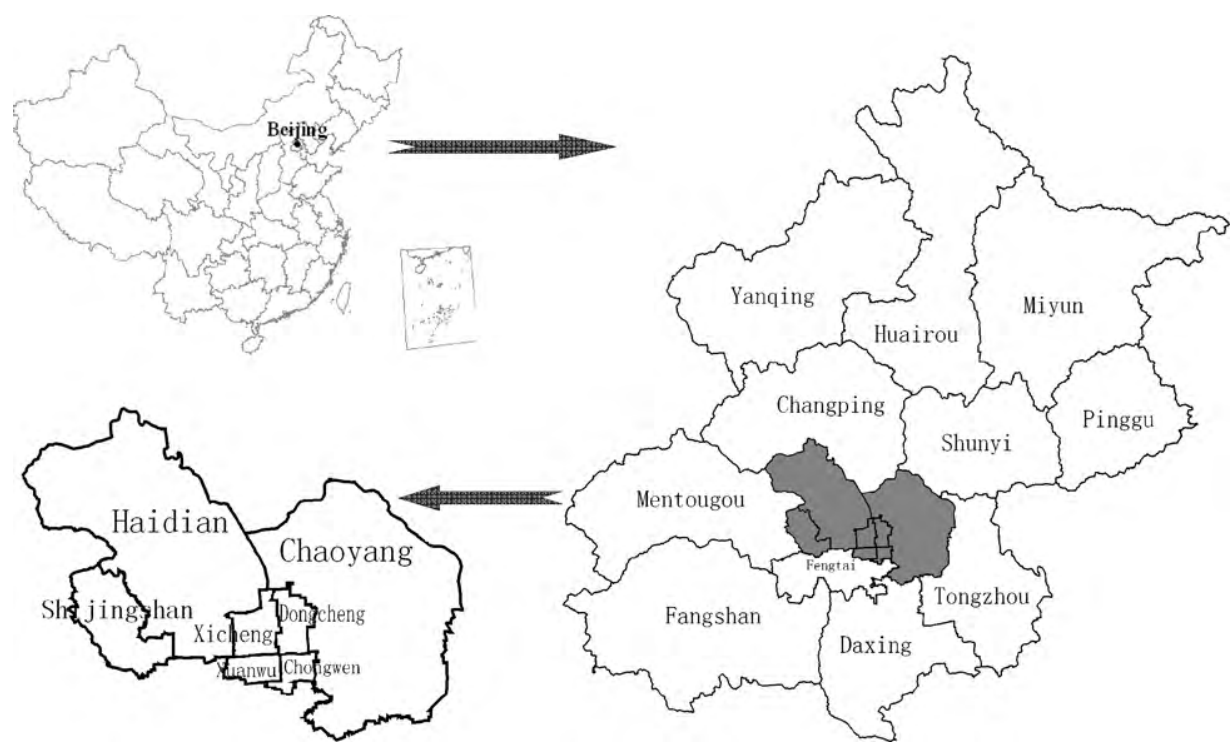

Fig. 3. Geographical location of Beijing city. 
Table 1

Material use amount of residential buildings per unit area for different architectural structures (unit: t/100 m²).

\begin{tabular}{|c|c|c|c|c|c|c|c|}
\hline Types of structure & Cement & Steel & Timber & Brick & Gravel & Sand & Total \\
\hline Masonry-concrete & $14.9 \pm 0.1$ & $2.5 \pm 0.4$ & $0.7 \pm 0.1$ & $37.5 \pm 8.7$ & $36.9 \pm 3.5$ & $44.5 \pm 3.2$ & $136.9 \pm 16.8$ \\
\hline Steel-concrete & $24.6 \pm 2.3$ & $5.9 \pm 0.7$ & $0.8 \pm 0.1$ & $8.2 \pm 3.4$ & $60.7 \pm 5.5$ & $41.7 \pm 2.9$ & $141.9 \pm 14.8$ \\
\hline
\end{tabular}

\section{Analysis of the flow dynamics of residential building system}

The main purposes of this dynamic analysis are to examine paths, throughputs and transformation efficiency of material flows in its processes such as inputs, transformation, accumulation and outputs in the system, so as to adjust and optimize inputs and outputs, and to enhance the use efficiency of energy and materials and to reduce environmental impacts.

In detail, we need to examine the following in this research in a given period: (1) types and quantity of imported constructive materials; (2) use level of materials per unit building area and its influencing factors; (3) efficiency of transformation and accumulation of imported materials; (4) types and quantity of buildings from newly built, reformed or demolished; (5) amount, types and sources of building wastes.

\subsection{Basic situation of urban residential buildings in Beijing city}

In 2008, urban population in Beijing has reached 14.4 million. The built-up area of the city is $1310.9 \mathrm{~km}^{2}$, and GDP per capital reached 63029 RMB yuan (1 US dollar=6.9 RMB yuan currently). Beijing is an ancient city, and its development experienced more than 3000 years. However, the period of rapid development only dropped within the past 30 years (after 1978).

During 60 years from 1949 to 2008, the newly built residential area in Beijing reached $3.7 \times 10^{8} \mathrm{~m}^{2}$ (Fig. 2). The amount of newly built residential area increased a little before 1978, and began to rise after 1978. There was a period of rapid development between 2004 and 2008 in which the finished area of residential buildings increased up to 35 million $\mathrm{m}^{2}$ from 20 million $\mathrm{m}^{2}$, and the finished area of buildings during the period from 1979 to 2008 accounted for $92.5 \%$ of that during the period from 1949 to 2008 . For per capita living area, it was only around $4 \mathrm{~m}^{2}$ before 1949 , and then rose significantly from $4.6 \mathrm{~m}^{2}$ in 1979 to $21.6 \mathrm{~m}^{2}$ in 2008 For architectural structures. There were mainly multi-storey buildings with masonry-concrete structure before 1979. Afterwards, buildings with steel-concrete structures increased year by year among which some high-rise residential buildings increased much faster.

\subsection{Site investigations and data collection}

Urban residential building system in Beijing consists of different architectural structures that are made of various types of constructive materials. This study took into account of six main constructive materials of cement, steel, sand, gravel, timber and bricks, and two dominate architectural structures of masonry-concrete, and steel-concrete for survey.

We organized and processed data of investigation in every 5 -year period, and randomly selected samples of residential buildings which were built from 1949 to 2008 and located mainly among districts of Xicheng, Dongcheng, Xuanwu, Chongwen, Haidian, Chaoyang and Shijingshan (Fig. 3). The main items of building survey included their name, age, storey, architectural structure and area. For these sampling buildings, we obtained the necessary data by examining the uses of constructive materials from project design maps from Beijing Municipal Construction Archives.

\subsection{Estimation of material use per unit area of the investigated residential buildings}

According to the survey data of sampling buildings, we calculated total use amount of the materials used in different types of buildings, then calculated use amount of six main constructive materials per unit area (cement, steel, gravel, sand, timber and bricks). This use mainly included materials that were used only by the main body of buildings (such as walls, foundation or substructure, roof, etc.).

Table 2

Independent samples $T$-test for material use amount of two typical architecture structures.

\begin{tabular}{|c|c|c|c|c|c|}
\hline & \multicolumn{2}{|c|}{ Levene's test for equality of variances } & \multicolumn{3}{|c|}{ T-test for equality of means } \\
\hline & $F$ & Sig. & $t$ & df & Sig. (two-tailed) \\
\hline \multicolumn{6}{|c|}{ Cement } \\
\hline EV & 6.09 & .02 & -13.11 & 21 & .00 \\
\hline EVN & & & -13.53 & 15.1 & .00 \\
\hline \multicolumn{6}{|l|}{ Steel } \\
\hline EV & 1.67 & .21 & -14.57 & 21 & .00 \\
\hline EVN & & & -14.86 & 18.8 & .00 \\
\hline \multicolumn{6}{|l|}{ Timber } \\
\hline EV & 1.22 & .28 & -3.42 & 21 & .00 \\
\hline EVN & & & -3.46 & 20.1 & .00 \\
\hline \multicolumn{6}{|l|}{ Brick } \\
\hline EV & 15.18 & .00 & 10.78 & 21 & .00 \\
\hline EVN & & & 10.43 & 12.7 & .00 \\
\hline \multicolumn{6}{|l|}{ Gravel } \\
\hline EV & 1.69 & .21 & -12.18 & 21 & .00 \\
\hline EVN & & & -12.42 & 18.7 & .00 \\
\hline \multicolumn{6}{|l|}{ Sand } \\
\hline EV & .19 & .67 & 2.19 & 21 & .04 \\
\hline EVN & & & 2.18 & 20.2 & .04 \\
\hline
\end{tabular}

Note: EV: equal variances assumed; EVN: equal variances not assumed. 


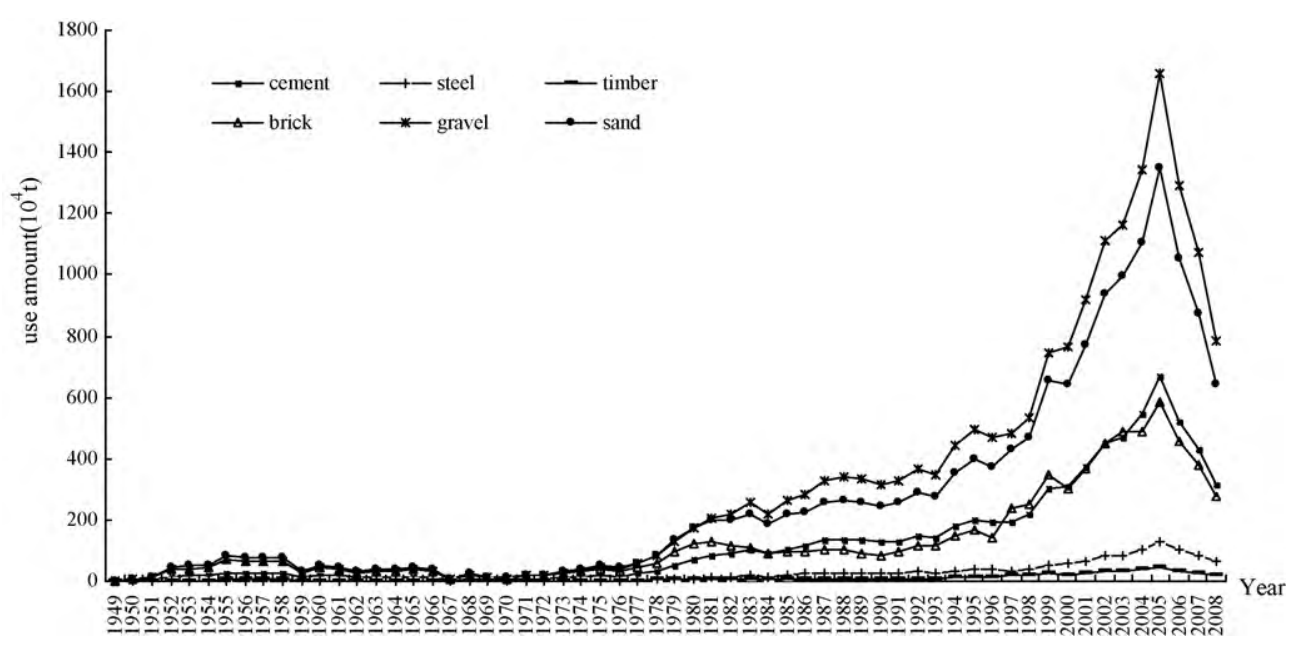

Fig. 4. The uses of six main constructive materials from 1949 to 2008 in the central areas of Beijing city.

We calculated average use amount per unit area for each type of buildings with two typical architectural structures. It was shown that buildings with steel-concrete structure consumed much more constructive materials than buildings with the masonry-concrete architectural structures. In addition, buildings with steel-concrete structure also consumed more steel than that with masonry-concrete structure, and reaches 2.4 times quantity of the buildings with masonry-concrete structure. However, buildings with masonry-concrete structure consumed much more bricks than that with steel-concrete structure, which is 4.6 times quantity of the buildings with steel-concrete structure (see Table 1). Furthermore, we make an independent samples $T$-test between the two types of building structures in Table 2. As shown in the table, the use amounts of cement, steel, brick gravel, timber and sand have significant difference between the two types of structures.

\section{Analyzing results}

\subsection{Inputs of residential building system in Beijing}

When analyzing total inputs of residential building system in Beijing, we just needed to multiply the total area of buildings and the quantity of material use per unit area. For the requirements of anti-earthquake, safety and constructing expenses, there existed a basic distribution of architectural struc- ture among the investigated buildings in Beijing as follows: buildings with 1-6 storied were mainly masonry-concrete; 7 and over 7-storied was mainly steel-concrete structure. Therefore we made the following assumptions: 1-6 storied were calculated by masonry-concrete structure, and 7 and over 7 storied were calculated by steel-concrete structure. This assumption was also manifested with the actual results of the building surveys we conducted. In addition, the following formulae were used to calculate total amount of material uses.

material use amount of buildings with certain type of architectural structure

$$
\begin{aligned}
& =\text { total area of certain type of buildings } \\
& \times \text { material use amount per unit area }
\end{aligned}
$$

total material use amount per year

$$
=\sum \text { material use amount of each type of buildings per year }
$$

It was shown that total amount of constructed area for residential buildings remained at a relatively low level before 1979, and so did their amounts of material uses. After that time, the inputs of all kinds of building materials experienced a rapid growth and

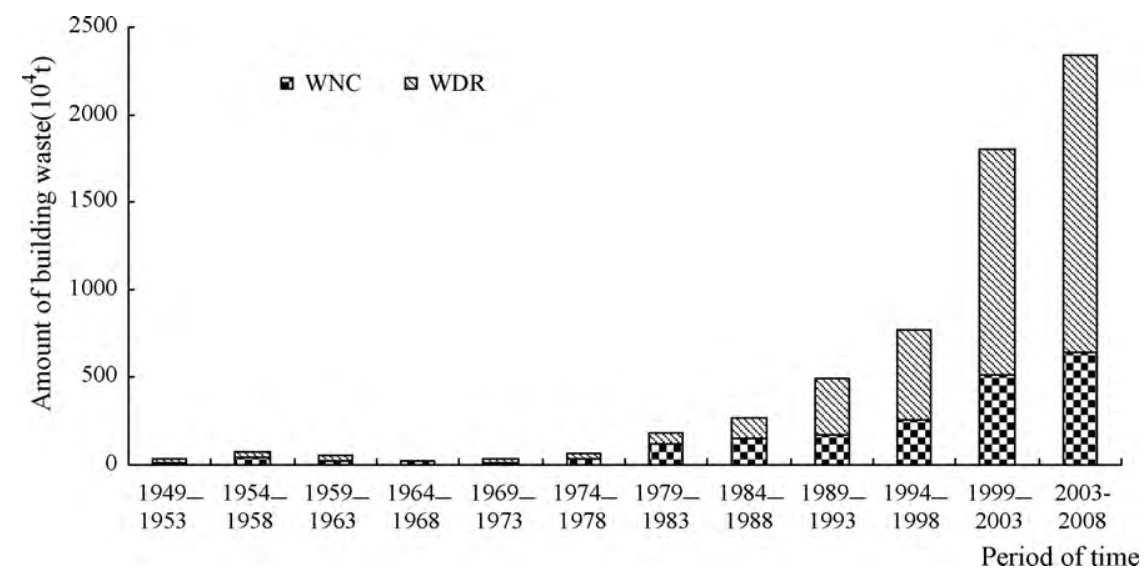

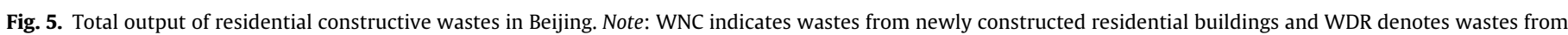
reformed and demolished residential buildings for different periods. 


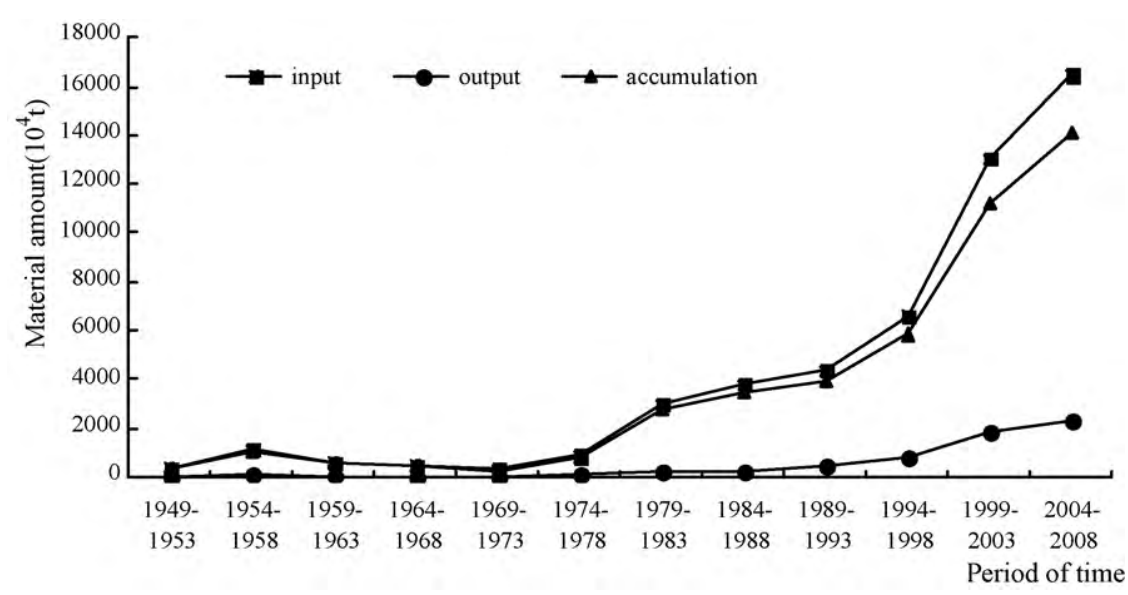

Fig. 6. The accumulation of residential building system over time in Beijing.

its growth rate accelerated gradually. Among the six main building materials, sand and gravel had the largest amount of input, the next was cement, and the smallest was timber, but input of bricks was relatively stable and there was a considerable increase after 2000. From 1999 to 2008, the total input of building materials reached 211.0 million tons. The input amount of different building materials such as cement, steel, sand and gravel doubled in the 10 years and the input of bricks was 2.9 times of that of the former 10 years (Fig. 4).

\subsection{Outputs of residential building system}

\subsubsection{Output of building wastes from different stages}

Outputs from residential building system were mainly in a form of wastes. The amount of wastes generated was different in different periods of a building life cycle.

(1) Reformation and demolishment of old residential buildings A large number of old residential buildings entered their periods of renovation and demolishment during the renewal of Beijing old urban areas in the past more than 10 years and resulted in lots of constructive wastes such as waste bricks, mortar, plaster, concrete blocks, waste steel and scrap timbers, etc. It was estimated that per $1 \mathrm{~m}^{2}$ of demolished buildings generated 1 ton of wastes in Beijing (Lu, 1999).

(2) New construction of residential buildings

New construction of residential buildings was another main source of building wastes. It was estimated that per $1 \times 10^{4} \mathrm{~m}^{2}$ of newly constructed residential buildings generated 500-600 tons of building wastes (Lu, 1999).

\subsubsection{Total output of residential buildings}

We used the data of total area of newly constructed and demolished buildings to calculate the total annual output of constructive wastes (Fig. 5). According to the calculated results, the total amount of constructive wastes was small before 1979. There were only 569,800 tons of constructive wastes totally from 1974 to 1978 . It was due to a small amount of reformed or demolished buildings, and at the same time constructive wastes mostly generated from newly constructed buildings. Moreover, there was a rapid increase in the total amount of wastes since 1979. The amount of constructive wastes reached 41.4 million tons during the period from 1999 to 2008, which was 9.2 times of that generated from 1979 to 1988 , and 3.3 times of that generated from 1989 to 1999 and the amount of wastes generated from reformation and demolishment was much larger than that generated from newly constructed buildings (Fig. 5). This was due to two aspects: firstly, a lot of old buildings had reached the end of their lifetime needing to be dismantled; secondly, the rapid construction of the city resulted in an earlier removal of old residential buildings to meet big demand for urban land-use.

\subsubsection{Management of building wastes}

According to the city statistics data, the amount of building wastes accounted for $30-40 \%$ of the total amount of urban wastes in Beijing, and this amount increased year by year. At present, a large amount of constructive wastes generated were largely transported and disposed in the forms of open dumps or landfill in suburban areas or rural areas of Beijing. This not only had great negative environmental impacts, but also led to a great waste of resources and an occupation of some highly productive land. To solve these problems, the municipal government of Beijing has made some efforts in the two aspects: the first was to reduce the amount of wastes from their sources; the second was to improve recycling or reuse of wastes.

\subsection{Transformation and accumulation of residential building system}

\subsubsection{Transformation and accumulation}

After entering into residential building system, most of constructive materials were changed to be components of buildings, and a small part of them formed constructive wastes. The capacity of transformation and accumulation was the basic characteristic of residential building system. We calculated total accumulated amount in the system by the difference between its input and output (Fig. 6).

From Fig. 6, it was found that increasing trend of accumulating amount and output amount in residential building system had a positive relation with increasing trend of input amount. There were respectively correlation coefficients of 1.00 for accumulating amount $(P<0.001)$ and 0.99 for output amount $(P<0.001)$. A time-series regression analysis on input, accumulation and output amount showed that there was an increasing trend of exponential functions. Their expressions were as follows:

input amount $=e^{526+0.35 t}$

where $t$ is a temporal variable of year, $R=0.91$ and $P<0.001$;

output amount $=e^{248+0.41 t}$

where $t$ is a temporal variable of year, $R=0.92$ and $P<0.001$;

accumulation amount $=e^{521+0.35 t}$

where $t$ is a temporal variable of year, $R=0.90$ and $P<0.001$. 


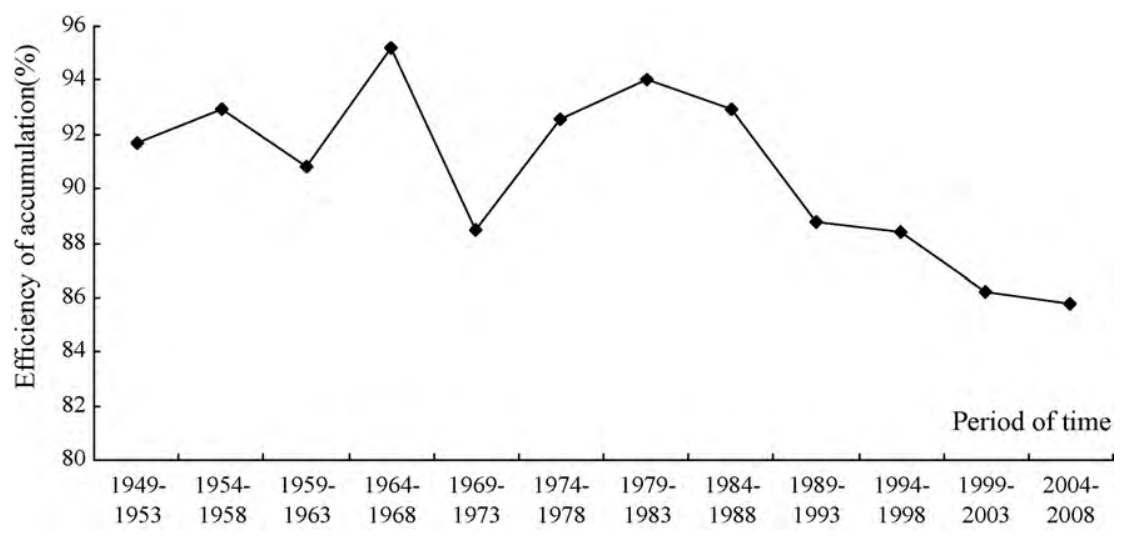

Fig. 7. Efficiency of accumulation in residential building system from 1949 to 2008 in Beijing.

The total amount of accumulation was small with a low rate of growth before 1979; and the amount of accumulation began to rise rapidly in the period between 1979 and 1998, and its total amount reached 214 million tons. The rate of accumulation had a further increase after 1999, and the total amount of accumulation was 253.9 million from 1999 to 2008 , which occupied more than 56.5\% of that during the whole 60 years. In such a short period, there was a large amount of materials entering and becoming accumulated in the system.

\subsubsection{Efficiency of accumulation}

We defined the efficiency of accumulation of residential building system as follows:

efficiency of accumulation $=\frac{\text { input-output }}{\text { input }}=1-\frac{\text { output }}{\text { input }}$.

Efficiency of accumulation is an indicator expressing the capacity of transformation and accumulation for materials imported. If efficiency of accumulation is high, there will be more imported materials to be transformed and accumulated as components of the system, and the corresponding constructive wastes may become less. In contrast, there will be more output of constructive wastes if efficiency of accumulation is low, and further has greater pressure and negative impacts on urban environment. In order to estimate the significance level of the indicator, its mean square deviation was also calculated by the following formula:

$d($ efficiency of accumulation $)=\frac{d(\text { output })}{\text { input }- \text { output }} \times \frac{d(\text { input })}{\text { input }^{2}}$

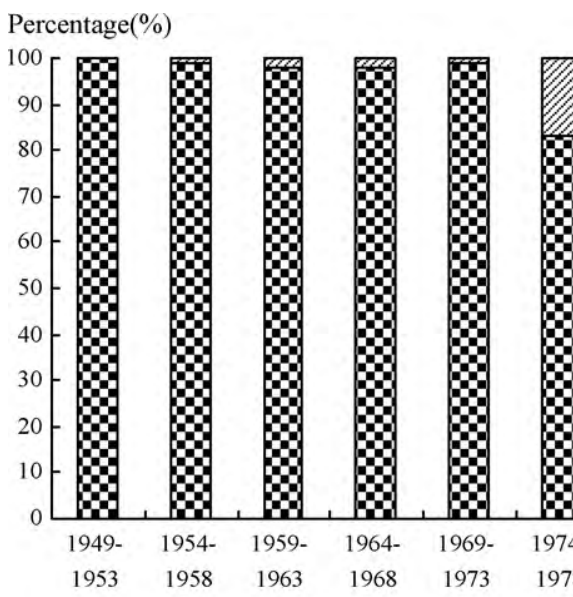

And the variance for the indicator of efficiency of accumulation can be calculated by the following formula:

$$
\begin{aligned}
\operatorname{var}(\text { efficiency of accumulation })= & \left(\frac{\text { output }_{\text {input }}^{2}}{\text { in }^{2} \times \operatorname{var}(\text { input })}\right. \\
& +\left(\frac{1}{\text { input }}\right)^{2} \times \operatorname{var} \text { (output) }
\end{aligned}
$$

From our calculating results (see Fig. 7), both of the mean square deviations for input and output amount were less than $10 \%$. Therefore, the mean square deviation for the indicator of efficiency of accumulation was less than $2 \%$. The probability distribution of the indicator of efficiency of accumulation can be hypothesized as normal distribution, and the degree of confidence is $95 \%$ within the doubled mean square deviation, which means that the variation of a declining trend for the indicator of efficiency of accumulation was significant. Furthermore, a time-series regression analysis on efficiency of accumulation over time showed that there was a decreasing trend of exponential function, and its expression was as follows:

efficiency of accumulation $=e^{-0.06-0.006 t}$

where $t$ is a temporal variable of year, $R=0.66$ and $P<0.05$. It was shown that the total amount of accumulation was not large and efficiency of accumulation fluctuated during the period between 1949 and 1974. In the decade from 1974 to 1984, accumulative efficiency of the system gradually increased from the level of 88 to $94 \%$. During the 25 years from 1985 to 2008, there was a significant 

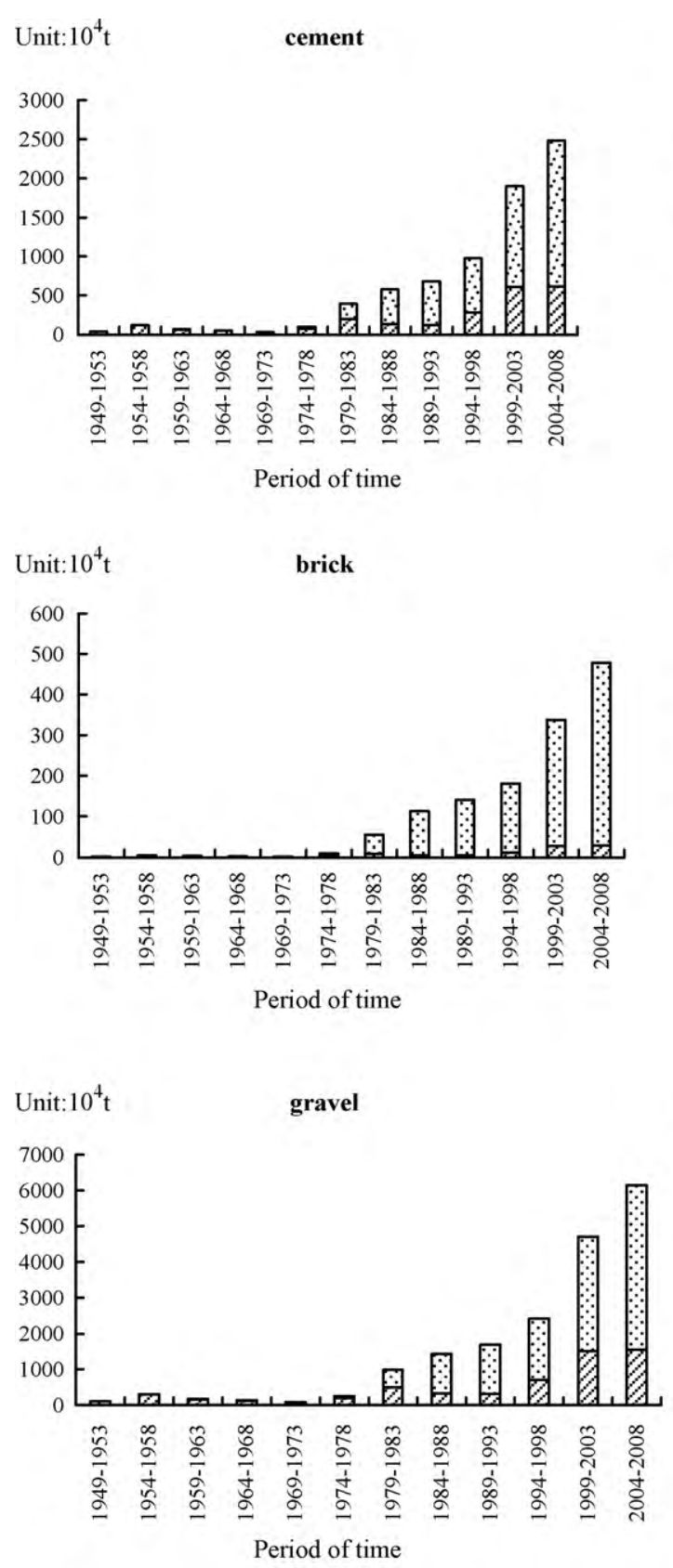

: masonry-concrete
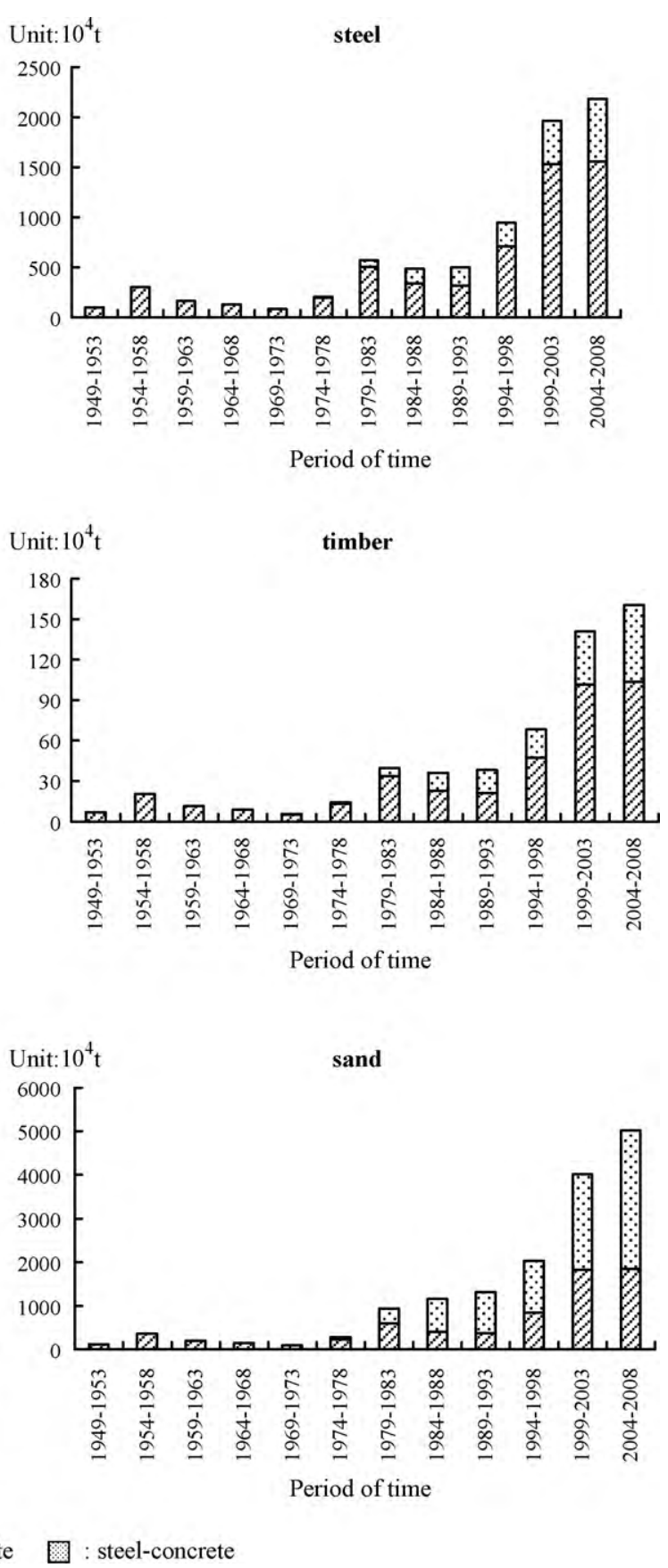

Fig. 9. Differences in the accumulated amount between six main building materials for buildings with different architectural structures over time in Beijing.

increase in the accumulated amount of materials, but efficiency of accumulation declined, which meant a decline in use efficiency of constructive materials and a generation of more constructive wastes. This trend indicated that the efficiency of residential building system in Beijing was not in a trend of growth.

\subsubsection{Transformation and accumulation of materials in residential building system}

Different materials are transformed into different components of residential building system. And different architectural structures of buildings greatly influence accumulation of materials. Therefore, the proportion of buildings with different architectural structures in the studied buildings affected the accumulated amount of every type of materials. It was shown that the main types of architectural structures before 1973 was masonry-concrete among the constructed buildings and the proportion of the buildings with steel-concrete structures increased while masonry-concrete decreased between 1949 and 1973. After 1984 , the proportion of buildings with masonry-concrete structure was less than $40 \%$, and the proportion of the buildings with steel-concrete structure was greater in newly constructed buildings. During the period from 2003 to 2008, the proportion of buildings with steel-concrete structure reached $64.7 \%$ and that with masonry-concrete structure decreased to $35.3 \%$ (Fig. 8).

It was also shown that, there were generally larger accumulated amount of materials for steel-concrete and masonry-concrete structures in Beijing, and the accumulated amount of sand and gravel had a relatively larger percentage in the total. The accumulative levels of constructive materials in two typical architectural structures were different and the accumulated amount of bricks in 
buildings with masonry-concrete structure was much greater than the other architectural structure while the accumulated amount of steel and concrete were greater in buildings with steel-concrete structures than that in masonry-concrete structure (Figs. 8 and 9).

From 1949 to 2008, uses of all kinds of materials were in a rising trend, but their increased amount was different. The increase in the use amount of cement and steel mainly came from an increase of buildings with steel-concrete structure since a relatively larger amount of steel and cement are needed for steel-concrete structure (Fig. 9).

\subsubsection{Factors influencing efficiency of transformation and accumulation in residential building system}

Generally, there are three major factors affecting accumulated amount of materials in Beijing residential building system, total constructed amount of residential buildings, use of materials per unit area and efficiency of accumulation.

4.3.4.1. Total amount of constructed residential buildings. Total amount of residential buildings has a direct impact on transformation and accumulation of materials. The result of correlation statistical analysis between accumulated amount and newly constructed area of residential buildings indicated that there was a correlation coefficient of 0.98 between them $(P<0.01)$, and therefore, an increase in total amount of residential buildings inevitably led to an increase in total accumulated amount of material use.

4.3.4.2. Use of materials per unit area. Use of materials per unit area is another important factor influencing transformation and accumulation of constructive materials. For an individual residential building, there is different use level of materials for its different components, which determines the use of materials per unit area. According to the data of building surveys in Beijing, we compared the differences of material use among different components of an individual building. It was shown that, for foundation of a single building, steel-concrete structure used more bricks, cement, sand, gravel and steel than that of masonry-concrete. For wall body, masonry-concrete structure used more bricks while the steel-concrete structure used more cement, sand, gravel and steel. For roofs, the steel-concrete structure used more of all types of materials than the masonry-concrete structure, and there was no use in bricks for two structures for the surveyed buildings. For stairs, the situation was the same as that of roofs (Table 3 ).

For total use of five kinds of building materials, the total material use of wall body from large to small was masonry-concrete and
Table 3

Difference in use of materials for each component of the surveyed individual newly constructed residential building $\left(\mathrm{t} / 100 \mathrm{~m}^{2}\right)$.

\begin{tabular}{lrrrr}
\hline Components of building & Foundation & Wall body & Roof & Stair \\
\hline Masonry-concrete & & & & \\
Bricks & 1.3 & 36.8 & 0.0 & 0.0 \\
Cement & 3.5 & 2.9 & 4.8 & 0.1 \\
Sand & 5.4 & 10.9 & 8.2 & 0.2 \\
Gravel & 10.6 & 4.6 & 16.6 & 0.3 \\
Steel & 0.5 & 0.4 & 2.1 & 0.0 \\
Subtotal & 21.2 & 55.6 & 31.6 & 0.6 \\
Steel-concrete & & & & \\
Bricks & 1.4 & 20.4 & 0.0 & 0.0 \\
Cement & 3.8 & 5.6 & 8.0 & 2.0 \\
Sand & 7.0 & 12.2 & 15.4 & 2.0 \\
Gravel & 10.9 & 2.2 & 16.3 & 1.6 \\
Steel & 1.5 & 2.8 & 2.3 & 3.3 \\
Subtotal & 24.5 & 42.8 & 42.0 & 7.2 \\
\hline
\end{tabular}

Note: There was no use of timber in the investigated buildings.

steel-concrete; the total material use of foundation from large to small was steel-concrete and masonry-concrete, so were the roofs and stairs.

For an individual building with masonry-concrete structure, its foundation had less use of all the materials; its wall body had much more use of bricks, and gravel; and its roofs had more use of sand and gravel, and there was very little use of materials for stairs. For a building with steel-concrete structure, its foundation had more use of all the materials; its wall body had more use of steel, sand and cement; and its roofs had more use of steel, sand, and cement; its stairs had more use of all the materials (Table 3 ).

4.3.4.3. Accumulative efficiency of residential building system. There are many factors having influences on efficiency of material accumulation. Selection of materials, constructive technology and different types of architectural structures all affect transformation and accumulation of materials. When input is definite, enhancing of efficiency of accumulation helps to fully utilize building materials and to reduce emission of constructive wastes and their environmental impacts.

Architectural structure is an important factor to affect efficiency of material accumulation, and a comparison was done between the increase rate of material accumulation with the increase rate of constructed building area (Fig. 10) to indicate that when the constructed building area increased or decreased, the total amount of material accumulation correspondingly grew or declined. In contrast, there was a relative small amount of generation of con-

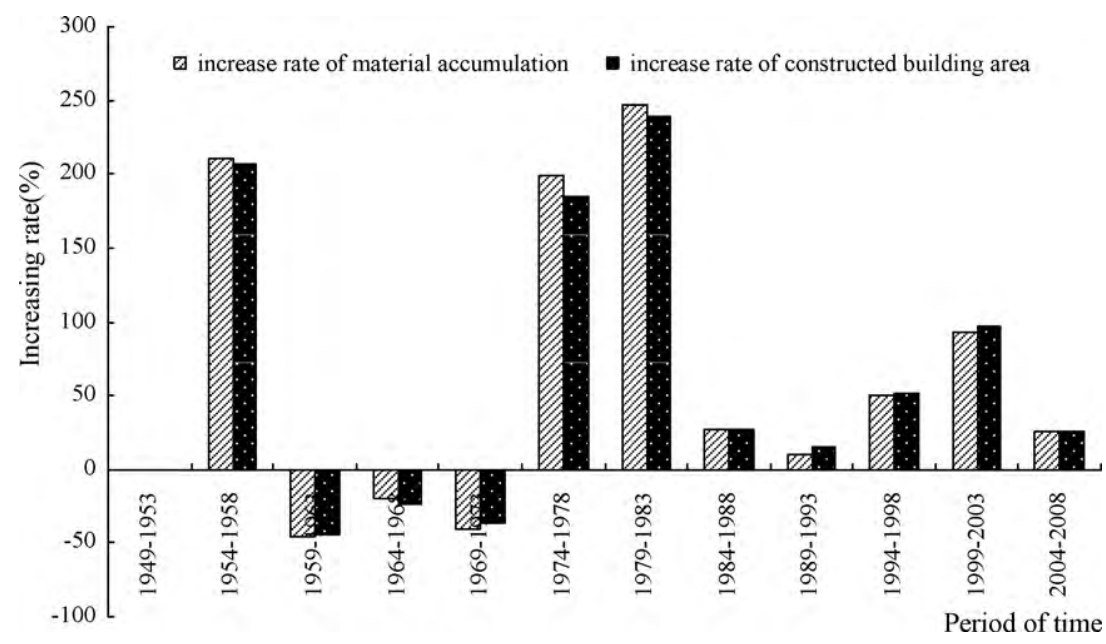

Fig. 10. A comparison between increase rates of material accumulation and constructed building area over time in Beijing. 


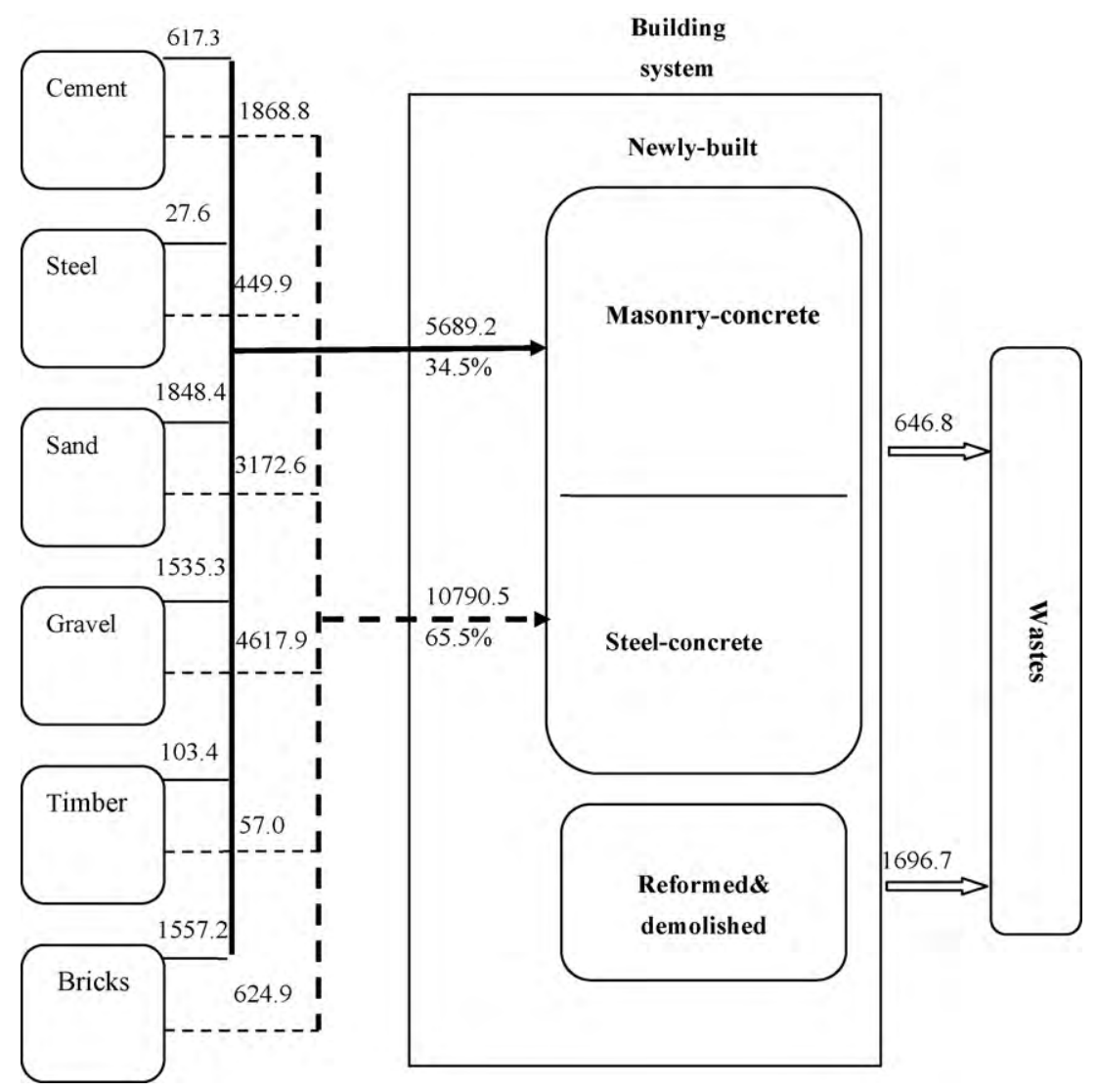

Fig. 11. The dynamic material flows chart of residential building system from 2004 to 2008 in Beijing.

struction wastes before 1984 so that the increase or decrease rate of constructed building area was not greater than that of material accumulation except for the period of 1964-1968. During the period from 1984 to 2008 , there was an obvious increase in the proportion of steel-concrete structure and a decline in the proportion of masonry-concrete structure (also see Fig. 8), and this change in the proportion of architectural structures made the increase rate of total amount of material inputs rise. The increasing rate of accumulation was, nevertheless, not larger than that of constructed building area due to a rapid growth of generation of constructive wastes (also see Fig. 5). There were three factors affecting the dynamics of increasing rate of building material accumulation and constructed building area: (i) changes in the composition of different architectural structures for buildings; (ii) changes in the reformation and demolishment of buildings that altered the generation of building wastes as an output and affected the increasing rate of accumulation; (iii) changes in new-built buildings, reformed and demolished buildings, and the proportion of architectural structures for buildings, together determined changes in the increasing rate of accumulation and the increase rate of constructed building area. In any case, material accumulation and constructed building area usually assumed a consistent trend of change.

\subsection{Dynamic model of material flows for the residential building system in Beijing}

According to the above results of analysis, we used the data of the period between 2003 and 2008 to further establish a building material flows chart, which describes a complete dynamic process of residential building system in Beijing from 2003 to 2008 (Fig. 11).

\section{Discussions}

One of the most important factors determining the use of building materials is architectural structures. In the urban residential building system of Beijing, architectural structures changed in an overall trend that the proportion of steel-concrete structures gradually increased while the proportion of masonry-concrete structure decreased since 1949. This change in architectural structures determined characteristics of material flow processes of residential building system and their use of materials. In particular, buildings with steel-concrete structure had larger amount of material use in comparison to masonry-concrete structures.

In general, the uses of six major building materials in Beijing's residential building system during the period from 1949 to 2008 had the following characteristics: in the total use amount of cement, the buildings with steel-concrete structure accounted for $68.4 \%$, and masonry-concrete structure $31.6 \%$. In the total use amount of steel, the buildings with steel-concrete structure accounted for $92.1 \%$, and masonry-concrete structure $7.9 \%$. In the total use amount of gravel, the buildings with steel-concrete structure accounted for $68.2 \%$, and masonry-concrete structure $31.8 \%$. In the total use amount of sand, the buildings with steel-concrete structure accounted for $55.1 \%$, and masonry-concrete structure 44.9\%; In the total use amount of timber, the buildings with steel-concrete structure accounted for $28.2 \%$, and masonry-concrete structure $71.8 \%$. In the total use amount of bricks, the buildings with steel-concrete structure accounted for $22.3 \%$, and masonry-concrete structure $77.7 \%$. Obviously, the use of materials in Beijing's residential building system was mainly determined by their architectural structures, which also determined environmental impacts of residential buildings in Beijing. 
For the inputs of Beijing's residential building system, from 1949 to 2008 , constructive materials imported into the system reached $5.10 \times 10^{8} \mathrm{t}$, among which, there was an import of $1.65 \times 10^{8} \mathrm{t}$ from 2003 to 2008 , accounting for $32.4 \%$ of the total. Since 1978 , especially after the 1990s, the increase rate of import gradually rose. Within the 10 years from 1999 to 2008, the total import increased by $200 \%$ compared to the former 10 years from 1989 to 1998 . Moreover, the use of sand and gravel was more than other materials during the period from 1999 to 2008. The steel-concrete structure became a dominate type of newly constructed buildings, which occupied more than $60 \%$ of the total use amount of constructive materials.

For the accumulation of Beijing's residential building system, the total amount of building materials transformed and accumulated in the system increased together with the increase of total constructed building area during the period from 1949 to 2008. The total amount of accumulation rose up to $4.7 \times 10^{8} \mathrm{t}$, and the accumulative rate is $92.5 \%$, of which, there was a huge amount of $1.4 \times 10^{8} \mathrm{t}$ from 2003 to 2008 , accounting for $29.9 \%$ of the total. Before 1988, the average efficiency of accumulation stayed at $92 \%$. But after that it decreased, indicating that the system's efficiency of materials use became to decrease.

For the outputs of Beijing's residential building system, some amount of materials used went into the environment in the form of wastes. There was a total output of $3.9 \times 10^{7} \mathrm{t}$ during the period from 1949 to 2008. Most of the import was transformed into components of residential buildings.

Building wastes were generated not only from newly constructed buildings, but also from reformation and demolishment of old buildings. Since 1989, the old residential buildings had been reformed or demolished massively in Beijing. The wastes from reformation and demolishment were larger than that from newly constructed buildings, and the former was approximately twice as the latter. Especially during the period from 2003 to 2008, there was a largest output of $2.3 \times 10^{7} \mathrm{t}$, accounting for $60.8 \%$ of the total. In general, urban residential buildings have their limited lifetime, when demolished, they become transformed into wastes as output of the system, which is one of the main sources of urban environmental impacts.

\section{Conclusions}

In Beijing, urban buildings accounted for over half of artificial facilities, and their flows of materials were usually supported by a large amount of inputs from the outside Beijing, which often caused some environmental problems. For example, the majority of clay bricks come from highly productive arable land, directly affecting the stability and health of suburban agro-ecosystems. Additionally, bricks are impossible to be transformed back to highly productive clay again and used by growing crops. Many substances of steel, sand and gravel are extracted and used as building materials, not reused or recycling after the demolishment of buildings, but abandoned or land-filled.

Our research indicated that the dynamic processes of input, accumulation and output of Beijing's residential building system from 1949 to 2008 kept an increase all the time, especially, assumed a large rise after 1978 while the urban construction also grew rapidly. The growth of urban residential buildings in Beijing consumed a large amount of natural resources and generated lots of wastes. The consumption of constructive materials and efficiency of material use were mainly determined by architectural structures, and the residential buildings with different architectural structures have the different per unit area material uses, different levels of material accumulation and different amounts of wastes generation. For different parts of a single residential building, this pattern of input, accumulation and output of constructive materials also applies.

In Beijing, the city's future development of residential building system possibly assumes three scenarios as follows: (i) The growth of residential building system continues along with the city's development in the next 10-20 years, and the input and accumulation level of building materials will keep increasing rapidly, and the output as wastes generation from urban building construction, reformation and demolition also kept increasing. Therefore, it is necessary to seek a good technological or managerial way of enhancing recycling or reusing capacity of building wastes from residential building system. (ii) The growth of residential building system ceases, and the technologies needs to be developed or introduced to make construction wastes become a certain useful kinds of substitutes for constructive materials so as to reduce the total consumption of natural resources from the outside city; (iii) The city's development shrinks, there can exist a surplus of constructive wastes as reused materials for urban developmental demand and makes the city face a huge ecological risk of disposing of these wastes. Until now, Beijing municipal government has been taken lots of relevant measures such as development and use of new green building materials, prolonging the lifetime of residential buildings, recycling or reusing constructive wastes as much as possible, and enhancing efficiency of waste disposal and landfill, etc., which have produced some good results for promotion of sustainable building construction in Beijing.

From a viewpoint of life cycle, the life cycle of residential building system in Beijing mainly consists of extraction of raw materials, processing and transportation of building materials, use and maintenance of residential buildings, disposal and recycling of building wastes. There are different characteristics of material uses and environmental impacts in the different stages of life cycle of buildings. This study focused only on construction and reformation or demolition of residential buildings with main two types of architectural structures in Beijing during the period from 1949 to 2008, without covering temporally the other stages of residential buildings, further research on, for example, material use characteristics of buildings with other architectural structures (for buildings with steel structure that becomes more and more in Beijing building system) and other functional types of buildings such as industrial buildings and public buildings, will be gradually conducted in future time. Our research work will be helpful to offer a basis for the design and management of sustainable building system in Beijing and other cities in China in the future.

\section{Acknowledgements}

This research was supported by National Foundation of Natural Sciences of China (70873121) and the State Key Laboratory of Urban \& Regional Ecology (SKLURE2008-1-01). This work was also supported by 973 National Basic Research Program of China (Grant number: 2005CB724206) and Knowledge Innovation Project of Chinese Academy of Sciences (KZCX2-YW-324).

\section{References}

Asif M, Muneer T, Kelley R. Life cycle assessment: a case study of a dwelling home in Scotland. Building and Environment 2007;42:1391-4.

Al-Rabghi OM, Douglas $\mathrm{CH}$. Energy simulation in buildings: overview and BLAST example. Energy Conversion and Management 2001;42:1623-35.

Baccini P, Brunner PH. Metabolism of the anthroposphere. Heidelberg, NY: SpringerVerlag; 1991.

Baccini P. A city's metabolism: towards the sustainable development of urban systems. Journal of Urban Technology 1997;4:27-39.

Barles S. Urban metabolism of Paris and its region. Journal of Industrial Ecology 2009;13:898-913.

Beijing Municipal Bureau Statistics. Beijing statistical yearbook. Beijing: China Statistics Press; 2009. 
Boyden S, Millar S, Newcombe K, O'Neill B. The ecology of a city and its people: the case study of HongKong. Canberra: Australian National University Press; 1981. Chwieduk D. Towards sustainable-energy buildings. Applied Energy 2003;76:211-7.

Decker EH, Elliott S, Smith FA, Blake DR, Rowland FS. Energy and material flow through the urban ecosystem. Annual Review of Energy and the Environment 2000;25:685-740.

Erlandsson M, Borgb M. Generic LCA-methodology applicable for buildings, constructions and operation services-today practice and development needs. Building and Environment 2003;38:919-38.

Erlandsson M, Levin P. Environmental assessment of rebuilding and possible performance improvements effect on a national scale. Building and Environment 2004;39:1453-65.

Haberl H, Fischer-Kowalskia M, Krausmann F, Weisz H, Winiwarter V. Progress towards sustainability? What the conceptual framework of material and energy flow accounting (MEFA) can offer. Land Use Policy 2004;21:199-213.

Huang SL, Hsu WL. Materials flow analysis and emergy evaluation of Taipei's urban construction. Landscape and Urban Planning 2003;62:61-74.

Johnstone IM. Energy and mass flows of housing: a model and example. Building and Environment 2001;36:27-41.

Lu Kai-an. Status and utilization of building wastes in China. Construction Technology (Beijing) 1999;28:44-5.

Morel JC, Mesbah A, Oggero M. Building houses with local materials: means to drastically reduce the environmental impact of construction. Building and Environment 2001;36:1119-26.

Meillaud F, Gay JB, Brown MT. Evaluation of a building using the emergy method. Solar Energy 2005;79:204-12.

Mitchell VG, Mein RG, McMahon TA. Modelling the urban water cycle. Environmental Modelling \& Software 2001;16:615-29.

Müller DB. Stock dynamics for forecasting material flows-case study for housing in The Netherlands. Ecological Economics 2006;59:142-56.
Newcombe K, Kalina JD, Aston AR. The metabolism of a city: the case of Hong Kong. AMBIO 1978;7:3-15.

Newman PWG. Sustainability and cities: extending the metabolism model. Landscape and Urban Planning 1999;44:219-26.

Osmani M, Glass J, Prize ADF. Architects' perspectives on construction waste reduction by design. Waste Management 2008;28:1147-58.

Pulselli RM, Simoncini E, Pulselli FM, Bastianoni S. Emergy analysis of building manufacturing, maintenance and use: em-building indices to evaluate housing sustainability. Energy and Buildings 2007;39:620-8.

Sahely HR, Dudding S, Kennegy CA. Estimating the urban metabolism of Canadian cities: greater Toronto area case study. Canadian Journal of Civil Engineering 2003;30:468-83.

State Statistical Bureau. Statistical yearbook of China. Beijing: China Statistical Press 2009.

Theodosiou G, Koroneos C, Moussiopoulos N. Alternative scenarios analysis concerning different types of fuels used for the coverage of the energy requirements of a typical apartment building in Thessaloniki, Greece. Part II: life cycle analysis. Building and Environment 2005;40:1602-10.

Tiwari P. Energy efficiency and building construction in India. Building and Environment 2001;36:1127-35.

Ulgiati S, Brown MT. Monitoring patterns of sustainability in natural and man-made ecosystems. Ecological Modelling 1998;108:23-6.

Warren-Rhodes K, Koenig A. Escalating trends in the urban metabolism of Hong Kong: 1971-1997. AMBIO 2001;30:429-38.

Wolman A. The metabolism of cities. Scientific American 1965;213:179-88.

Zhang Y, Yang ZF, Yu XY. Evaluation of urban metabolism based on emergy synthesis: a case study for Beijing (China). Ecological Modelling 2009;220:1690-6.

Zhao P, Tong JF. Requirements of Green buildings for constructive materials. China's Building Materials Technology 2003;12:1-10. 